Article

\title{
Application of Microwave in Hydrogen Production from Methane Dry Reforming: Comparison Between the Conventional and Microwave-Assisted Catalytic Reforming on Improving the Energy Efficiency
}

\author{
Seyyedmajid Sharifvaghefi ${ }^{1,+}{ }^{+}$Babak Shirani ${ }^{1,+}{ }^{+}$Mladen Eic ${ }^{1}$ and Ying Zheng ${ }^{2, *}$ \\ 1 Department of Chemical Engineering, University of New Brunswick, Fredericton, NB E3B 5A3, Canada \\ 2 Department of Chemical and Biochemical Engineering, Thompson Engineering Building, \\ Western University, London, ON N6A 5B9, Canada \\ * Correspondence: ying.zheng@uwo.ca; Tel.: +1(519)661-82138 \\ + These authors share equal first authorship.
}

Received: 22 June 2019; Accepted: 18 July 2019; Published: 20 July 2019

\begin{abstract}
The microwave-assisted dry reforming of methane over $\mathrm{Ni}$ and $\mathrm{Ni}-\mathrm{MgO}$ catalysts supported on activated carbon (AC) was studied with respect to reducing reaction energy consumption. In order to optimize the reforming reaction using the microwave setup, an inclusive study was performed on the effect of operating parameters, including the type of catalysts' active metal and their concentration in the AC support, feed flow rate, and reaction temperature on the reaction conversion and $\mathrm{H}_{2} / \mathrm{CO}$ selectivity. The methane dry reforming was also carried out using conventional heating and the results were compared to those of microwave heating. The catalysts' activity was increased under microwave heating and as a result, the feed conversion and hydrogen selectivity were enhanced in comparison to the conventional heating method. In addition, to improve the reactants' conversion and products' selectivity, the thermal analysis also clarified the crucial importance of microwave heating in enhancing the energy efficiency of the reaction compared to the conventional heating.
\end{abstract}

Keywords: dry reforming methane (DRM); methane; carbon dioxide; microwave; conversion; catalyst; selectivity; thermal integration

\section{Introduction}

Applying methane dry reforming process for hydrogen production has received significant attention during the last decades as a result of increasing demand for clean and renewable energy [1-5]. In addition, the main reactants of the reforming reaction, methane and carbon dioxide, have tremendous effects on global warming, which necessitate controlling their concentration by converting them to a clean and sustainable source of energy, i.e., hydrogen. In addition to hydrogen, carbon monoxide is also another valuable product of methane dry reforming reaction that is further reacted to produce ultraclean fuels including gasoline, methanol, and dimethyl ether (DME) with negligible hazardous byproducts, e.g., aromatics [6,7]. Consequently, improving the $\mathrm{CO}_{2}$ reforming of methane is essential in terms of conversion, selectivity, and energy efficiency.

The carbon dioxide reforming of methane is an endothermic reaction, which requires huge external heat source (Equation (1)). Hence, applying novel techniques to perform the reaction with minimum input energy is necessary to improve the process efficiency and reduce the costs.

$$
\mathrm{CH}_{4}+\mathrm{CO}_{2} \Leftrightarrow 2 \mathrm{CO}+2 \mathrm{H}_{2} \quad \Delta \mathrm{H}_{298}=247 \mathrm{~kJ} / \mathrm{mol}
$$


A new technique that received extensive attention in the last decades is based on using microwave energy potential for reforming of methane and carbon dioxide. In comparison to conventional heating methods, microwave applications for producing the required heat for reaction is more energy efficient and less expensive. Utilizing microwaves also provides more advantages than conventional heating including a rapid process heating, reduced processing time and work space, more accurate and uniform heating, and high quality [8-11]. In contrast, microwave heating has limitations and technical problems such as selection of the type of materials with a broad adsorption bandwidth that strongly absorb microwaves [12]. As a result, an extensive study is required on the application of microwave setup to optimize and improve the methane-reforming process in terms of conversion and product selectivity.

The dry reforming reaction takes place in the presence of a catalyst, which enhances the conversion rate, syngas selectivity, and increases the reaction rate. The applied catalysts are based on expensive noble metals ( $\mathrm{Pt}, \mathrm{Pd}$, and $\mathrm{Ru}$ ) or less expensive metals including $\mathrm{Ni}, \mathrm{Co}, \mathrm{Fe}, \mathrm{Cr}$, and $\mathrm{Mo}$. The active metals are supported on metal oxides $\left(\mathrm{Al}_{2} \mathrm{O}_{3}, \mathrm{MgO}\right.$, and $\left.\mathrm{TiO}_{2}\right)$, rare-earth oxides $\left(\mathrm{CeO}_{2}\right)$, zeolites, silicate, and mesoporous carbon materials [13-15]. In spite of the important role of catalysts on increasing the reaction rate and enhancing reactants conversion, the syngas production from methane reforming still needs to be performed at extreme conditions of high pressure and temperature $[16,17]$. Hence, conventional techniques have to be improved by integrating new techniques in catalytic methane reforming. The microwave heating of catalysts provides similar conversion to those of conventional heating at reduced temperatures by selective heating of active sites. In addition, the coke formation rate is smaller than conventional heating methane reforming, confirming the supremacy of microwave heating methane reforming.

In this study, carbon dioxide reforming of methane was studied in a microwave field. In order to improve adsorption efficiency of the microwaves' energy, activated carbon was used as a support for $\mathrm{Ni}$ and $\mathrm{MgO}$ active metal catalysts. Combining microwave setup and $\mathrm{Ni}-\mathrm{MgO} / \mathrm{AC}$ catalysts improved reforming reaction in terms of selectivity and conversion rates. In order to optimize the selectivity of products and conversion of reactants and the energy efficiency of the system, the effects of operating parameters such as catalyst bed temperature, feed flowrate, and also the concentration of $\mathrm{Ni}$ and addition of $\mathrm{MgO}$ were investigated in detail. The catalysts were also conventionally heated to compare the conversion, selectivity, and thermal efficiency with those obtained using microwave.

\section{Results and Discussion}

Textural properties, reducibility, and Ni dispersion and surface area of the prepared catalysts are shown in Table 1. With an increase in nickel content of the catalysts, the surface area and pore volume was reduced. The $\mathrm{H}_{2}$ uptake of the catalysts, however, was found to to follow a different trend, increasing with nickel content of $15 \%$ and then being reduced for the catalysts with higher nickel content. The surface area for $\mathrm{NiMgO} / \mathrm{AC}$ was found to be the lowest $\left(539 \mathrm{~m}^{2} / \mathrm{g}\right)$, however the $\mathrm{H}_{2}$ uptake of this catalyst was only lower than the $\mathrm{Ni} / \mathrm{MgO} / \mathrm{AC}$ catalyst.

Table 1. Main characteristics of the synthesized catalysts.

\begin{tabular}{|c|c|c|c|c|c|c|}
\hline & $\begin{array}{l}\text { Surface Area } \\
\left(\mathrm{m}^{2} / \mathrm{g}\right)\end{array}$ & $\begin{array}{l}\text { Pore Volume } \\
\text { (cc/g) }\end{array}$ & $\begin{array}{l}\text { Average Pore } \\
\text { Diameter (Å) }\end{array}$ & $\begin{array}{c}\mathrm{H}_{2} \text { Uptake } \\
\text { (moles/g Catalyst) }\end{array}$ & $\begin{array}{c}\text { Ni Dispersion } \\
(\%)^{a}\end{array}$ & $\begin{array}{c}\text { Ni Surface } \\
\text { Area }\left(\mathrm{m}^{2} / \mathrm{g}\right)^{\mathrm{a}}\end{array}$ \\
\hline $\mathrm{AC}$ & 1287 & 0.894 & 27.78 & - & - & - \\
\hline $5 \mathrm{Ni} / \mathrm{AC}$ & 1004 & 0.733 & 29.20 & $2.80 \mathrm{E}-06$ & 0.66 & 2.19 \\
\hline $10 \mathrm{Ni} / \mathrm{AC}$ & 915 & 0.687 & 30.50 & $3.40 \mathrm{E}-06$ & 0.40 & 1.33 \\
\hline $15 \mathrm{Ni} / \mathrm{AC}$ & 871 & 0.654 & 31.76 & $4.56 \mathrm{E}-06$ & 0.36 & 1.19 \\
\hline $20 \mathrm{Ni} / \mathrm{AC}$ & 833 & 0.600 & 28.80 & $4.29 \mathrm{E}-06$ & 0.25 & 0.84 \\
\hline $25 \mathrm{Ni} / \mathrm{AC}$ & 665 & 0.473 & 28.46 & $4.16 \mathrm{E}-06$ & 0.20 & 0.65 \\
\hline $\mathrm{NiMgO} / \mathrm{AC}$ & 639 & 0.457 & 28.96 & $5.95 \mathrm{E}-06$ & 0.70 & 2.32 \\
\hline $\mathrm{Ni} / \mathrm{MgO} / \mathrm{AC}$ & 712 & 0.468 & 26.28 & $6.15 \mathrm{E}-06$ & 0.72 & 2.40 \\
\hline
\end{tabular}

a calculated by assuming $\mathrm{H}_{2} / \mathrm{Ni}$ atom ratio of 1 . 
The XRD profile of the $10 \mathrm{Ni} / \mathrm{AC}, \mathrm{NiMgO} / \mathrm{AC}$, and $\mathrm{Ni} / \mathrm{MgO} / \mathrm{AC}$ samples after $1 \mathrm{~h}$ of reduction in $\mathrm{H}_{2}$ flow is shown in Figure 1. The peak at 26.6 can be ascribed to the AC support. The peaks at 44.4 and 76.3 are attributed to the (111) and (220) diffraction planes of Ni phase. The remaning peaks are assigned to the $\mathrm{MgO}$ phase. Although both $\mathrm{NiO}$ and $\mathrm{MgO}$ have the same charactristric peaks, the intensity of the peaks suggests that the $\mathrm{NiO}$ phase in the fresh catalyst is mostly reduced to $\mathrm{Ni}$ in all of the tested catalysts.

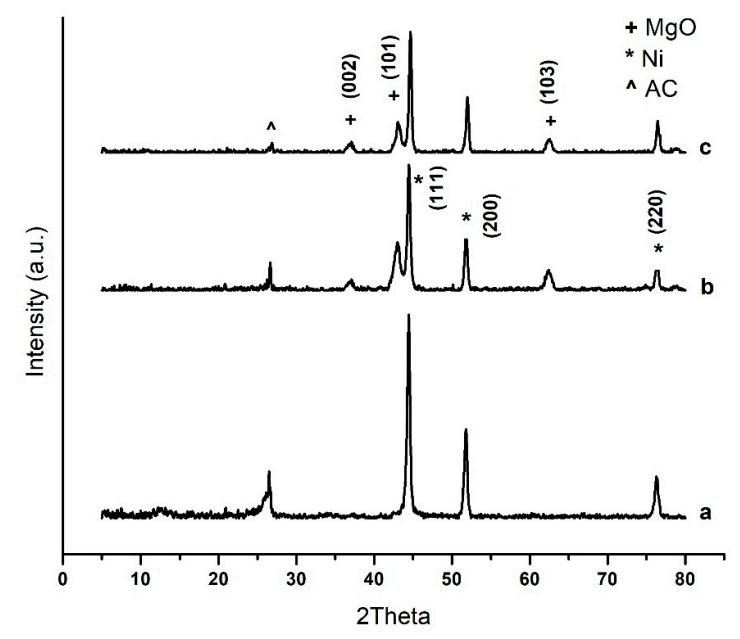

Figure 1. XRD profile of (a) $10 \mathrm{Ni} / \mathrm{AC},(\mathbf{b}) \mathrm{NiMgO} / \mathrm{AC}$, and (c) $\mathrm{Ni} / \mathrm{MgO} / \mathrm{AC}$.

Temperature programmed reduction (TPR) behaviors of calcined $10 \mathrm{Ni} / \mathrm{AC}, \mathrm{NiMgO} / \mathrm{AC}$, and $\mathrm{Ni} / \mathrm{MgO} / \mathrm{AC}$ catalysts were investigated as shown in Figure $2 . \mathrm{H}_{2}$ reduction for $10 \mathrm{Ni} / \mathrm{AC}$ catalyst shows the typical reduction peaks for $\mathrm{NiO}$ at $250{ }^{\circ} \mathrm{C}$ and $430{ }^{\circ} \mathrm{C}$, which have been related to the reduction of $\mathrm{Ni}^{3+}$ and $\mathrm{Ni}^{2+}$ to metallic nickel, respectively $[18,19]$. For $\mathrm{NiMgO} / \mathrm{AC}$ and $\mathrm{Ni} / \mathrm{MgO} / \mathrm{AC}$ catalysts, the first reduction peak is also observed at $250{ }^{\circ} \mathrm{C}$, suggesting that part of the $\mathrm{NiO}$ phase is not influenced by the $\mathrm{MgO}$. However, the second reduction peak is shifted to $740{ }^{\circ} \mathrm{C}$, which can be assigned to the $\mathrm{Ni}^{2+}$ ions on the outermost layer of the $\mathrm{MgO}$ [20]. The wider peak for $\mathrm{NiMgO} / \mathrm{AC}$ at this temperature indicates the reduction of $\mathrm{NiO}$ forms located in the subsurface layers of the $\mathrm{MgO}$ lattice, which is understandable considering that this catalyst was prepared through co-impregnation of $\mathrm{NiO}$ and $\mathrm{MgO}$ precursors. The higher dispersion of $\mathrm{NiO}$ in $\mathrm{NiMgO} / \mathrm{AC}$ and $\mathrm{Ni} / \mathrm{MgO} / \mathrm{AC}$ facilitates the formation of smaller crystallites, which are more strongly bonded and, consequently, lowering the reducibility. On 10Ni/AC with lower dispersion, $\mathrm{Ni}$ species are not so strongly bonded to the surface, thus presenting a higher reducibility.

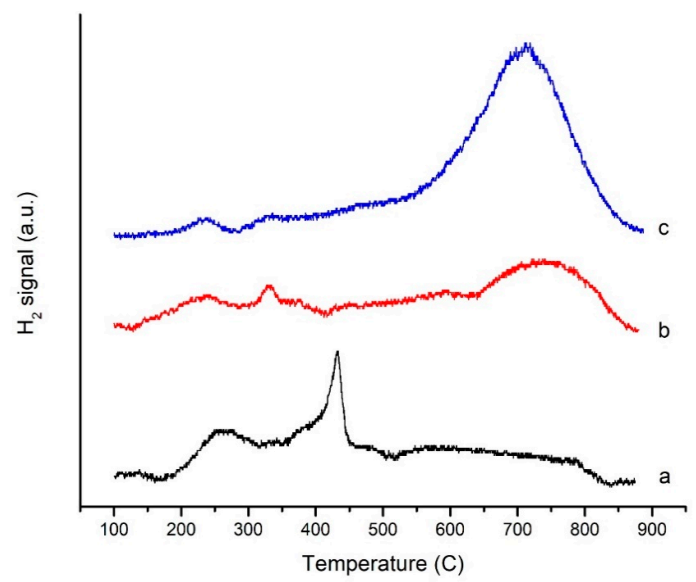

Figure 2. Temperature programmed reduction (TPR) profile of (a) 10Ni/AC, (b) NiMgO/AC, and (c) $\mathrm{Ni} / \mathrm{MgO} / \mathrm{AC}$. 


\subsection{Temperature Effect on Conversion and Product Selectivity}

The conversions of $\mathrm{CH}_{4}$ and $\mathrm{CO}_{2}$ over the synthesized catalysts at different temperatures using microwave as the heating medium, are shown in Figure 3a,b, respectively. It can be seen that the increase in temperature of reaction accelerates the reforming reaction resulting in higher conversion of the reactants at higher temperatures. As evidenced, among the Ni/AC catalysts, $15 \%$ nickel loading shows the highest conversion with $76 \%$ and $79 \%$ for $\mathrm{CH}_{4}$ and $\mathrm{CO}_{2}$, respectively. Conversions follow a decreasing trend with higher nickel content. The observed trend can be related to the $\mathrm{H}_{2}$ uptake and nickel dispersion results by these catalysts, which shows the same trend. The results indicate that with the increase in nickel content up to 15\% the number of available sites for the adsorption of the reacting gases was increased. However, with the addition of extra nickel to the catalyst, the nickel particles agglomerate and, therefore, the dispersion of the catalyst was reduced, resulting in lower active sites and lower conversion of the reactants.
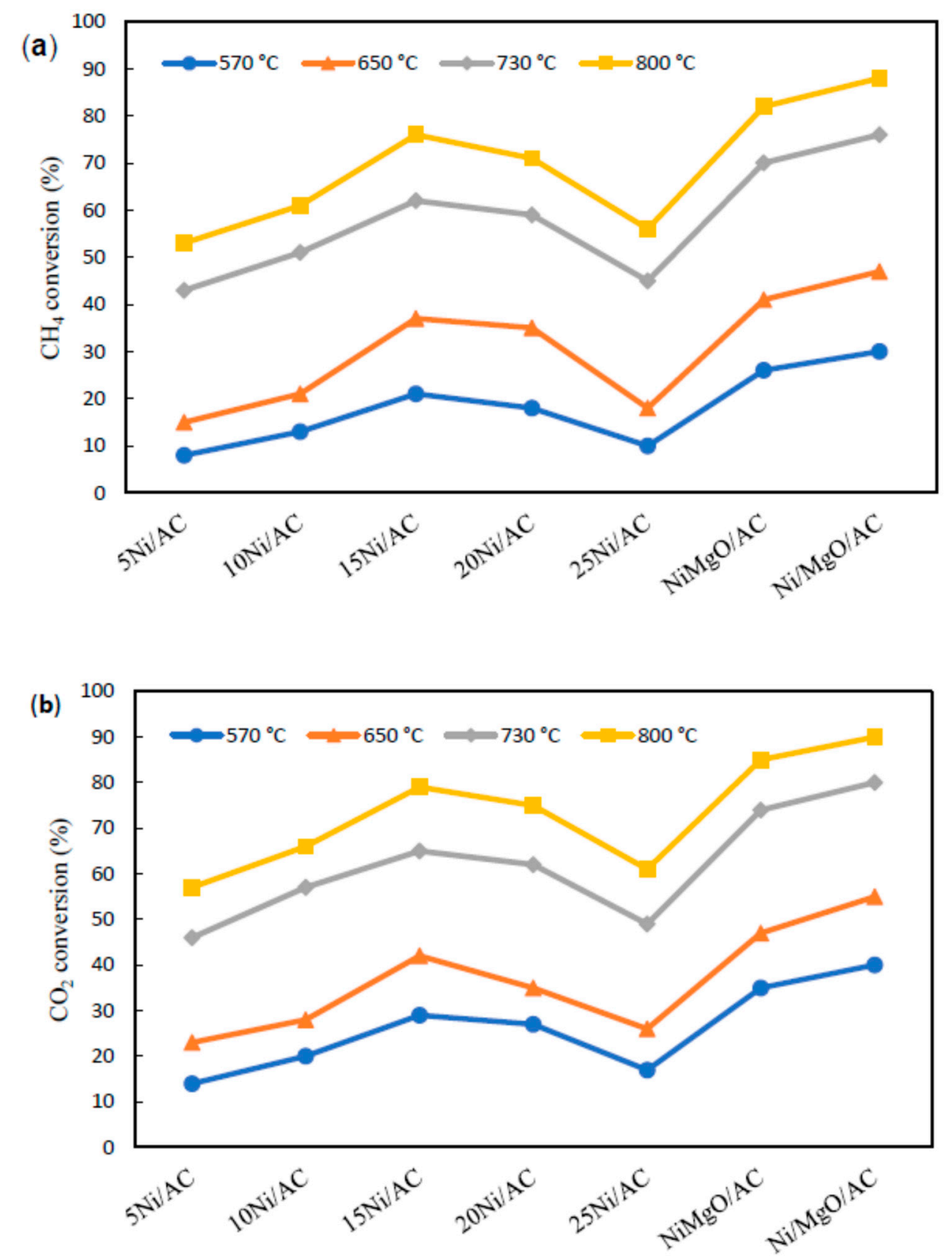

Figure 3. Cont. 


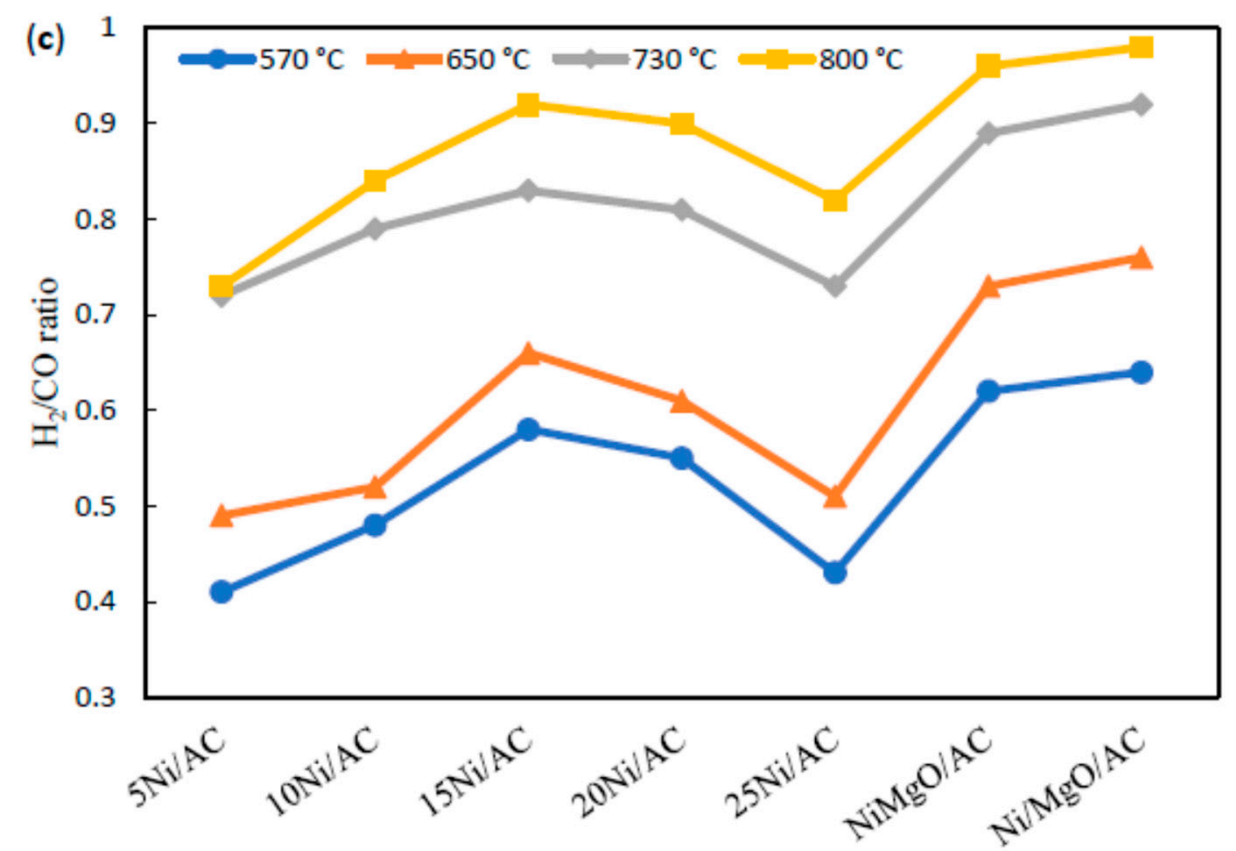

Figure 3. (a) $\mathrm{CO}_{2}$ and (b) $\mathrm{CH}_{4}$ conversions and (c) product selectivity as a function of temperature over the prepared catalysts using microwave heating.

The results show that the conversion of $\mathrm{CH}_{4}$ and $\mathrm{CO}_{2}$ increases almost linearly with nickel content of the catalysts (up to $15 \%$ ). Furthermore, the addition of $\mathrm{MgO}$ to the catalyst was found to have a positive impact on the activity of the catalysts increasing the $\mathrm{CH}_{4}$ conversion to $84 \%$ and $88 \%$ for $\mathrm{NiMgO} / \mathrm{AC}$ and $\mathrm{Ni} / \mathrm{MgO} / \mathrm{AC}$ catalysts. $\mathrm{H}_{2}$ uptake and dispersion results for these catalysts suggest that with the addition of $\mathrm{MgO}$, nickel dispersion over the $\mathrm{AC}$ support is enhanced and therefore the number of active sites for the reforming reactions is increased. Comparing $\mathrm{NiMgO} / \mathrm{AC}$ with $\mathrm{Ni} / \mathrm{MgO} / \mathrm{AC}$, the conversion for the later catalyst was found to be higher. This could be attributed to the fact that with co-impregnation of $\mathrm{NiO}$ and $\mathrm{MgO}$, parts of the $\mathrm{NiO}$ phase will be located beneath the $\mathrm{MgO}$ layers making them inaccessible to the reacting gases. Figure $3 \mathrm{c}$ shows the $\mathrm{H}_{2} / \mathrm{CO}$ ratio for the tested catalysts at various temperatures. The products ratio follows the same trend as the conversion of the reactants for the catalysts. Moreover, with temperature increase, the ratio was increased for all the catalysts.

\subsection{Effect of Heating Mechanism on Methane Reforming}

To study the effect of the microwave heating on the dry reforming reaction, the experiments were also carried out using conventional heating over $\mathrm{Ni} / \mathrm{MgO} / \mathrm{AC}$ catalyst. The results are shown in Figure 4 . The equilibrium conversions of $\mathrm{CO}_{2}$ and $\mathrm{CH}_{4}$ and the equilibrium molar ratio of $\mathrm{H}_{2} / \mathrm{CO}$ are also plotted in the Figure 4. Two reactions were considered to perform the equilibrium calculations, i.e., methane reforming by carbon dioxide and reverse water-gas shift reaction (RWGS). It is believed that the reforming of methane starts by decomposition of $\mathrm{CH}_{4}$ to carbonaceous deposits (Equation (2)). These deposits (at least those which are highly reactive), are gasified in the next step by $\mathrm{CO}_{2}$ (Equation (3)), giving rise to an in-situ regeneration of the active sites. The reverse water-gas shift reaction also occurs as a side reaction in which some of the $\mathrm{H}_{2}$ from the $\mathrm{CH}_{4}$ decomposition reacts with the $\mathrm{CO}_{2}$ to produce $\mathrm{H}_{2} \mathrm{O}$ and $\mathrm{CO}$ (Equation (4)). The equilibrium data were obtained from the thermodynamic analysis of the results.

$$
\begin{gathered}
\mathrm{CH}_{4} \rightarrow \mathrm{C}+2 \mathrm{H}_{2} \\
\mathrm{C}+\mathrm{CO}_{2} \rightarrow 2 \mathrm{CO} \\
\mathrm{CO}_{2}+\mathrm{H}_{2} \Leftrightarrow \mathrm{H}_{2} \mathrm{O}+\mathrm{CO}
\end{gathered}
$$



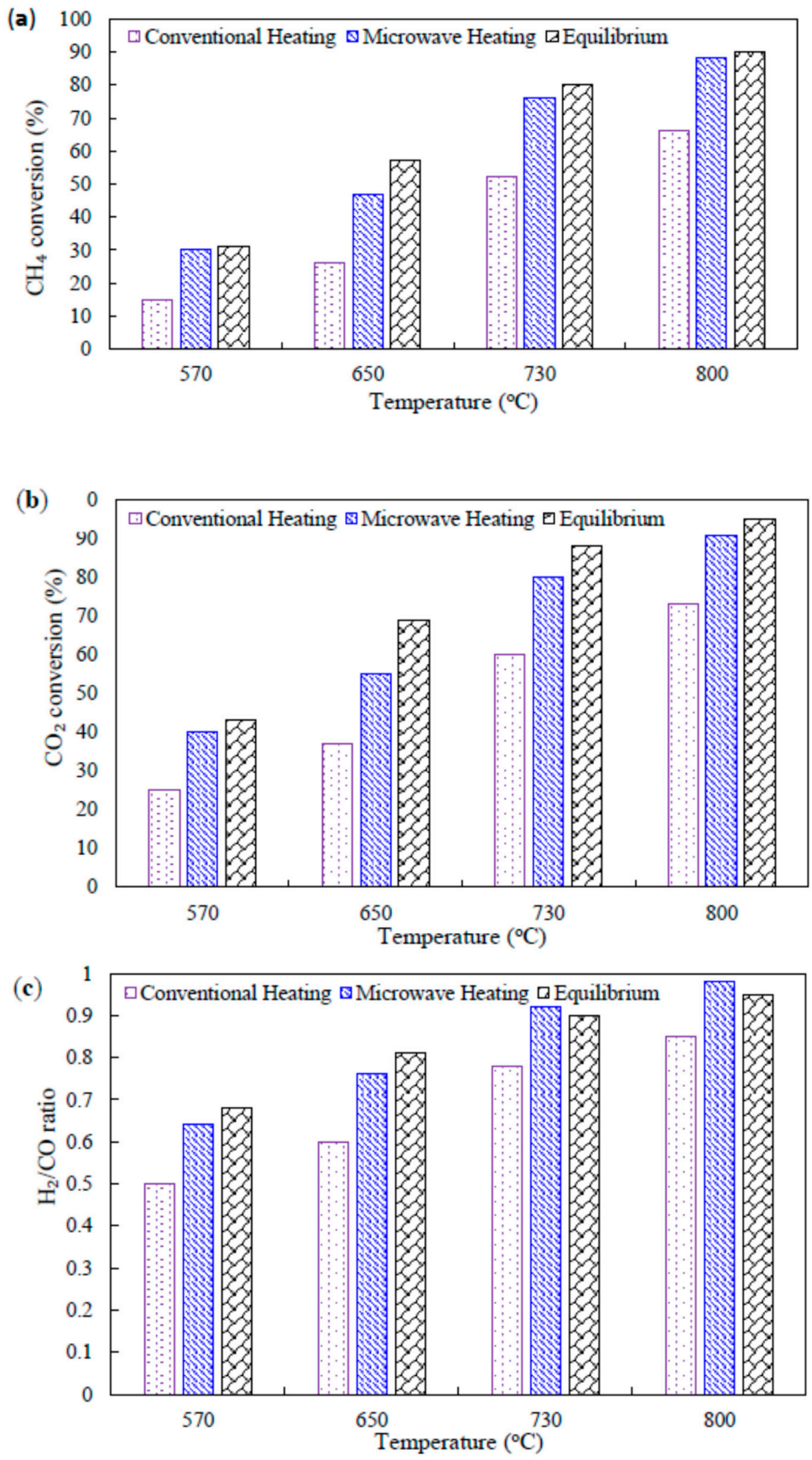

Figure 4. Comparison of microwave and conventional heating and equilibrium conditions for (a) $\mathrm{CO}_{2}$ and (b) $\mathrm{CH}_{4}$ conversions and (c) product selectivity as a function of temperature over $\mathrm{Ni} / \mathrm{MgO} / \mathrm{AC}$ catalyst and gas hourly space velocity (GHSV) of 33,000 mL/g cat.h.

Compared to the conventional heating, the conversion of methane and carbon dioxide were both higher using microwave heating. The difference in conversions can be explained by the differences between the heating mechanisms. In conventional heating, heat flux is responsible for energy transfer while microwave energy is directly transferred to the catalyst, without any heat flux. This results in higher temperature inside the catalyst compared to the temperature of the surrounding atmosphere near the surface, which can be translated to higher uniformity of heat distribution with respect to conventional heating [21,22]. Microwave heating also gives rise to micro-plasmas (also called hot spots) within the catalyst bed, where the temperature is higher than the measured average temperature in the bulk catalyst bed [23]. Such hot spots with higher temperature are reported to be responsible 
for enhancements in reaction rate, higher yields, and improved selectivity of heterogeneous catalytic reactions [24-26]. It is interesting to note that the conversions of $\mathrm{CO}_{2}$ and $\mathrm{CH}_{4}$ were always higher under microwave conditions with an almost constant difference with conventional heating. In contrast to conventional heating, microwave heating can generate multiple hot spots at the catalyst surface, where local reaction temperatures are higher than the overall reaction temperature.

In general, the results show that the $\mathrm{H}_{2} / \mathrm{CO}$ ratios increased when the temperature was raised. With conventional heating, the $\mathrm{H}_{2} / \mathrm{CO}$ ratio was lower than the equilibrium values. In contrast, the $\mathrm{H}_{2} / \mathrm{CO}$ ratio was higher than the equilibrium value in the higher temperature range under microwave heating. The $\mathrm{H}_{2} / \mathrm{CO}$ ratio was always found to be less than 1.0, an indication that the reverse water-gas shift reaction also occurred as a side reaction in addition to the methane reforming reaction. The variation of $\mathrm{H}_{2} / \mathrm{CO}$ ratios depends on the degree of competition between these reactions. Based on the thermodynamic data, both the $\mathrm{CH}_{4}$ reforming and the reverse water-gas shift reactions are endothermic. By increasing the temperature, both equilibrium constants $\left(\mathrm{K}_{\mathrm{p}}\right)$ increased, but the enhancement of $\mathrm{K}_{\mathrm{P}}$ for the $\mathrm{CH}_{4}$ reforming reaction was to a greater extent than that for the reverse water-gas shift reaction. This showed higher impact of temperature on the first reaction to produce hydrogen and carbon monoxide, giving a ratio closer to unity. The higher $\mathrm{H}_{2} / \mathrm{CO}$ ratio for microwave system can be explained by the creation of hot spots, which is similar to that from the thermal temperature effect. Using microwave heating, the reaction could occur at a higher temperature compared to the measured average temperature, so a higher $\mathrm{H}_{2} / \mathrm{CO}$ ratio could be reached, which can be even higher than the equilibrium value at the measured temperature.

\subsection{Effect of Varying Flow Rate on Methane Reforming}

The effect of varying the flow rate on the conversion of $\mathrm{CH}_{4}$ and $\mathrm{CO}_{2}$ at $650{ }^{\circ} \mathrm{C}$ for $\mathrm{Ni} / \mathrm{MgO} / \mathrm{AC}$ catalyst is shown in Figure 5. $\mathrm{CH}_{4}$ conversion decreased from $89 \%$ to $47 \%$ when gas hourly space velocity (GHSV) varies from $6700 \mathrm{~mL} / \mathrm{g}$ cat.h to $33,000 \mathrm{~mL} / \mathrm{g}$ cat.h. The results show a linear relation between the conversion of reactants and the flow rate of the inlet gases. The larger the GHSV, the lesser the contact time and the number of adsorbed reactants on the active sites. Unlike the results shown in Figure 4 where conversions of $\mathrm{CO}_{2}$ and $\mathrm{CH}_{4}$ were below equilibrium for GHSV of 33,000 mL/g cat.h, the reduction in flow rate leads to higher conversions than the calculated equilibrium. This shift in equilibrium for the methane reaction is also an indication of the presence of higher temperature at reacting sites (hot spots) than the measured average temperature of the bulk catalyst. With the decrease in GHSV, the $\mathrm{H}_{2} / \mathrm{CO}$ ratio was increased. This can be attributed to the increase in gas-solid contact time. With higher contact time, the water-gas shift reaction can occur to consume the produced CO and therefore increase the $\mathrm{H}_{2} / \mathrm{CO}$ ratio.

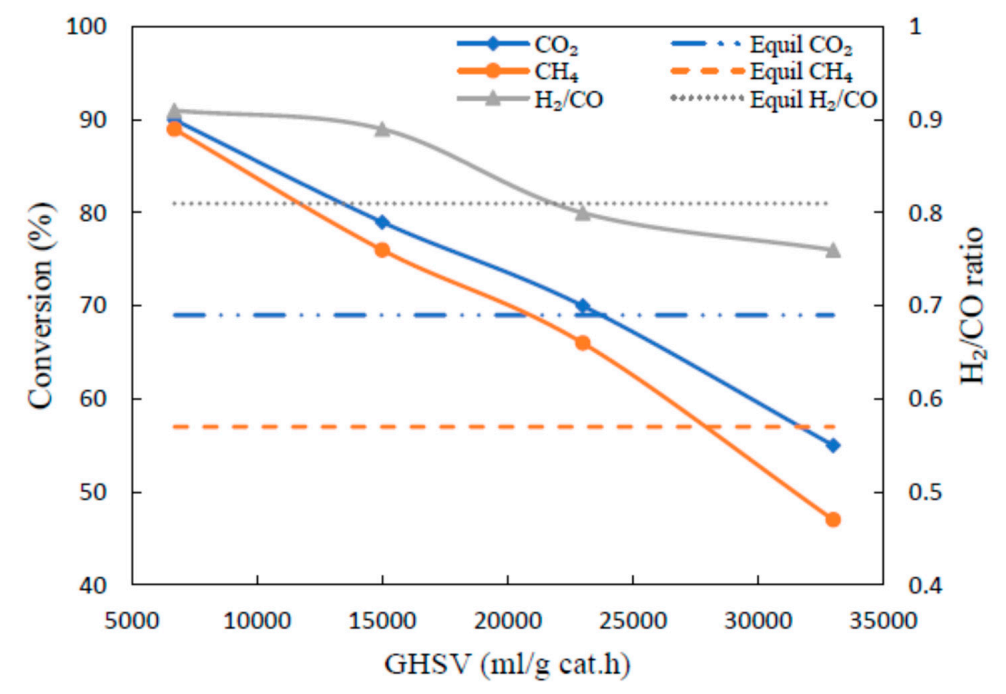

Figure 5. Effect of GHSV on Ni/MgO/AC catalyst performance for dry reforming of methane at $650{ }^{\circ} \mathrm{C}$. 


\subsection{Reactor Energy Efficiency}

Following the analysis presented by Durka et al. [27], an energy balance in macroscopic level is performed over the catalytic bed as follows:

$$
\sum_{i} n_{i_{I n}} \int_{T_{\text {amb }}}^{T_{\text {in }}} C_{p_{i}}(T) d T+Q_{\text {Input }}-Q_{\text {Loss }}=\Delta H_{r}^{T_{\text {amb }}}+\sum_{i} n_{\text {out }} \int_{T_{\text {amb }}}^{T_{\text {out }}} C_{p_{i}}(T) d T
$$

where $n_{i}$ is the number of moles of reactants and products, $T_{a m b}$ is the ambient temperature, $T_{i n}$ and $\mathrm{T}_{\text {out }}$ are the temperature of preheated reactants and products respectively, $\mathrm{Q}_{\text {Input }}$ is the heat provided to the reactor bed from the energy source, and $\mathrm{Q}_{\text {Loss }}$ is the heat dissipated to the surrounding. Since summation of the terms in left side of Equation (5) represents the net input energy into the reactor, Durka et al. [27] defined the energy efficiency as the fraction of input heat required to taking place the chemical reaction:

$$
\epsilon=\frac{\Delta H_{r}^{T_{\text {amb }}}}{\Delta H_{r}^{T_{a m b}}+\sum_{i} n_{\text {out }} \int_{T_{\text {amb }}}^{T_{\text {out }}} C_{p_{i}}(T) d T}
$$

where $\epsilon$ is the energy efficiency. In the present study, in addition to the reaction between methane and carbon dioxide, reaction 4 is also considered as the side reaction. By considering the carbon dioxide as the limiting reactant, the total heat released from Equations (1) and (4) at ambient temperature is calculated based on the total mole of reacted $\mathrm{CO}_{2}$. The results of the energy analysis for microwave and conventional heating reactor using 10Ni/AC and Ni/Mgo/AC catalysts are shown in Figure 6.

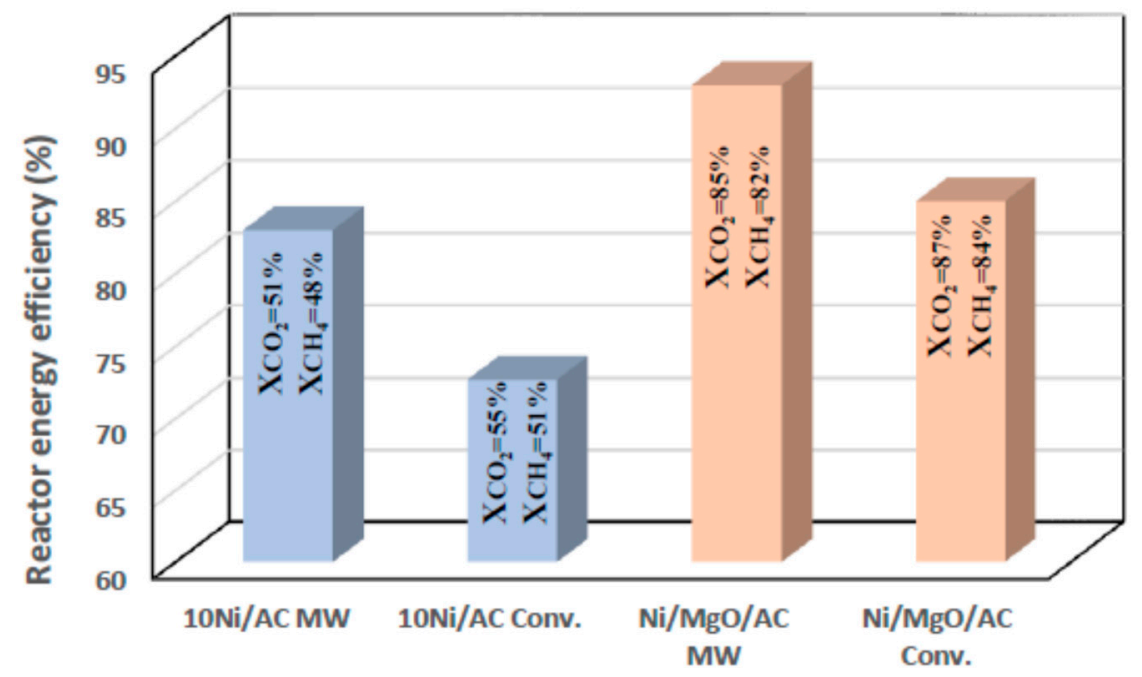

Figure 6. Energy efficiencies of microwave and conventional heating reactors using $\mathrm{Ni} / \mathrm{AC}$ and $\mathrm{Ni} / \mathrm{MgO} / \mathrm{AC}$ catalysts.

According to Figure 6, similar conversions of carbon dioxide and methane were selected to compare the energy efficiency of the two reactors. As a result, the heat of reaction is constant for both microwave and conventional heating technique and the only factor determining the reactor efficiency is the heat dissipating out of the reactor with the product (Equation (6)). The catalyst bed in the microwave reactor has a lower temperature than the one in the conventional heating reactor at equal conversion. The temperatures of the bed and product gases for microwave and conventional heating reactors applying $10 \mathrm{Ni} / \mathrm{AC}$ and $\mathrm{Ni} / \mathrm{MgO} / \mathrm{AC}$ catalysts are summarized in Table 2 . The results indicate that applying microwave for heating the catalysts results in lower overall reaction temperature at similar conversion. The reason is because of the significant temperature difference between the metal sites and support materials [27]. This temperature difference results in significantly higher temperature metal reaction sites than the support and gas phase, providing similar conversion to conventional 
reactor. The product temperature leaving the microwave reactor has a significantly lower temperature than those leaving the conventionally heated reactor. Consequently, based on Equation (6), the energy efficiency of the microwave reactor is greater than the conventional reactor. According to Figure 6, applying microwave heating resulted in 10\% improvement in energy efficiency for the bed filled with $10 \mathrm{Ni} / \mathrm{AC}$ catalyst and $8 \%$ for the bed of $\mathrm{Ni} / \mathrm{MgO} / \mathrm{AC}$ catalyst.

Table 2. Temperatures of the beds and product gases for microwave and conventional heating reactors.

\begin{tabular}{ccc}
\hline Catalyst & $\mathbf{T}_{\text {Bed }}\left({ }^{\circ} \mathbf{C}\right)$ & $\mathbf{T}_{\text {outlet-gas }}\left({ }^{\circ} \mathbf{C}\right)$ \\
\hline 10Ni/AC MW & 690 & 216 \\
10Ni/AC Conv. & 900 & 571 \\
Ni/MgO/AC MW & 695 & 212 \\
Ni/MgO/AC Conv. & 900 & 560 \\
\hline
\end{tabular}

Based on the results, it is clear that the microwave performs the reaction at a considerably lower temperature, and it is more energy efficient. However, it should be emphasized that the greater energy efficiency values do not necessarily means that the total energy required by microwave is less than the conventional heating reactors. Precise analysis on magnetron efficiencies and the energy loss in microwave conversion to heat has to be carried out to optimize the consumed energy by the microwave. Another advantage of applying the microwave in providing the reaction energy is the fast stabilization of the bed temperature. In comparison to conventional heating, where a few hours were required for the bed approaching the reaction temperature, the microwave heated the bed in a significantly shorter time and the reaction temperature was reached in a few minutes.

\section{Experimental}

\subsection{Catalyst Preparation and Characterization}

The $x$ Ni/AC with different Ni metal loading (x showing the Ni loading) were prepared by incipient wet impregnation. To prepare the $\mathrm{xNi} / \mathrm{AC}$, an aqueous solution containing the required mass of $\mathrm{Ni}\left(\mathrm{NO}_{3}\right)_{2} \cdot 6 \mathrm{H}_{2} \mathrm{O}$ (Sigma-Aldrich) was added to AC support (from Carbon Resources, coal based HCL washed) to make $5,10,15,20$, and $25 \mathrm{Ni} / \mathrm{AC}$. $10 \mathrm{Ni} / 10 \mathrm{MgO} / \mathrm{AC}$ (named Ni/MgO/AC herein) and $10 \mathrm{Ni}-10 \mathrm{MgO} / \mathrm{AC}$ (named $\mathrm{NiMgO} / \mathrm{AC}$ herein) catalysts were also prepared using the impregnation technique. The $\mathrm{Ni} / \mathrm{MgO} / \mathrm{AC}$ catalyst was synthesized by step-wise impregnation of first the $\mathrm{MgO}$ precursor $\left(\mathrm{Mg}\left(\mathrm{NO}_{3}\right)_{2} \cdot 6 \mathrm{H}_{2} \mathrm{O}\right.$, Sigma-Aldrich) followed by drying and calcination and then the addition of $\mathrm{Ni}$ precursor. $\mathrm{NiMgO} / \mathrm{AC}$ catalyst was prepared by co-impregnation of the $\mathrm{MgO}$ and $\mathrm{Ni}$ precursors. The catalysts were dried under continuous stirring at $90^{\circ} \mathrm{C}$ followed by drying at $120^{\circ} \mathrm{C}$ for $24 \mathrm{~h}$. The catalysts were eventually calcined at $700{ }^{\circ} \mathrm{C}$ with a ramp rate of $10{ }^{\circ} \mathrm{C} / \mathrm{min}$ under Argon stream for $5 \mathrm{~h}$. The catalysts were reduced at $600^{\circ} \mathrm{C}$ prior to their characterization. The textural properties of the prepared catalysts including BET surface area, pore volume, and pore diameter were measured by analyzing nitrogen adsorption-desorption isotherm at $77 \mathrm{~K}$ using Autosorb-1 (Quantachrome Instrument). In addition, the crystalline patterns of the catalysts were determined by X-ray diffraction (XRD) using a Bruker D8 Advance spectrometer. The diffractometer was equipped with a two-circle goniometer housed in a radiation safety enclosure. The X-ray source was a sealed, $2.2 \mathrm{~kW} \mathrm{Cu} \mathrm{X-ray}$ tube (X-ray wavelength $1.54 \mathrm{~A}$ ), maintained at an operating current of $40 \mathrm{kV}$ and $25 \mathrm{~mA}$. Samples were scanned in the range of $10-80^{\circ} 2 \theta$. A step size of $0.02^{\circ}$ and a step time of $1.0 \mathrm{~s}$ were used during the measurements. A peltier-cooled solid-state $[\mathrm{Si}(\mathrm{Li})]$ detector $(\mathrm{Sol}-\mathrm{X})$ with a useful energy range of 1 to $60 \mathrm{KeV}$ was used as the detector.

The hydrogen temperature programmed reduction (TPR) analysis for fresh catalysts were performed using Autosorb-1. For TPR analysis, about $10 \mathrm{mg}$ catalyst was regenerated in helium flow for $2 \mathrm{~h}$ at $120^{\circ} \mathrm{C}$. After removing the moistures, a helium stream that contained $5 \%$ hydrogen was introduced to the catalyst, and the system was heated up to $1000{ }^{\circ} \mathrm{C}$ with a heating rate of $10^{\circ} \mathrm{C} / \mathrm{min}$ 
to reduce the catalysts. The data regarding the temperature were collected using a thermocouple placed in a catalyst bed for accurate measurement. $\mathrm{H}_{2}$ chemisorption was performed to determine the nickel dispersion and nickel surface area. Further, $10 \mathrm{mg}$ of catalyst was first reduced in-situ at $600{ }^{\circ} \mathrm{C}$. The catalyst was subsequently purged with Ar flow at $600^{\circ} \mathrm{C}$ and was then cooled down to room temperature. Hydrogen was introduced again as a mixture of $\mathrm{H}_{2}(2 \%)$ and $\mathrm{Ar}(98 \%)$ with total flow rate of $50 \mathrm{~mL} / \mathrm{min}$. The catalyst was flushed with argon at $80^{\circ} \mathrm{C}$ and the temperature was raised afterwards with only argon flowing. The effluent gas from the catalyst bed was analyzed by mass spectroscopy (RGA 200, SRS) to determine the $\mathrm{H}_{2}$ concentration. Nickel dispersion and surface area were calculated considering the one-on-one adsorption of hydrogen on nickel atoms and atomic nickel cross-sectional area of $6.49 \times 10^{-20} \mathrm{~m}^{2} / \mathrm{Ni}$-atom by the following equations:

$$
\text { Dispersion }=\text { S. M. N/100W }
$$

$$
\text { Surface Area }=\text { N. L. C/100W }
$$

where $\mathrm{S}$ is a stoichiometric factor. That means, for example, in the case of $\mathrm{Ni}$ and $\mathrm{H}_{2}$ chemisorption, one molecule of $\mathrm{H}_{2}$ dissociates to give two atoms to be chemisorbed on $\mathrm{Ni}$ atoms. $\mathrm{N}$ is the amount of monolayer, experimentally obtained from flow experiments in $\mathrm{mol} / \mathrm{g}$ cat. $\mathrm{M}$ is the molecular weight of the metal $(\mathrm{g} / \mathrm{mol})$. $\mathrm{W}$ is the weight percentage of metal. $\mathrm{L}$ is the Avogadro number and $\mathrm{C}$ is the nickel cross-sectional area $\left(\mathrm{m}^{2} / \mathrm{Ni}\right.$-atom).

\subsection{Experimental Setup}

Microwave Setup: The schematic diagram of the microwave setup is shown in Figure 7. The dry reforming reaction was carried out in a fixed-bed quartz tube with an inside diameter of $16.9 \mathrm{~mm}$ and a length of $9.2 \mathrm{~mm}$. The catalysts $(0.9 \mathrm{~g})$ were placed in the waveguide channel and were heated by microwaves reaching the reaction temperature. The quartz wool was used to adjust the location of catalyst bed in the center of waveguide channel. The temperature of the catalyst bed was measured using a thermo-gun (model Milwakee M12) through an open window in front of the catalyst. The thermo-gun was calibrated before the experiments. The system was at atmospheric pressure and the applied microwave power was set to change the temperature of the catalyst. Prior to the catalytic reaction, the catalyst was reduced at $600^{\circ} \mathrm{C}$ for $2 \mathrm{~h}$ with hydrogen flow of $50 \mathrm{~mL} / \mathrm{min}$. After heating the catalysts to the reaction temperature, a mixture of methane-carbon dioxide (1:1) with a total flowrate of $500 \mathrm{~mL} / \mathrm{min}$ was heated in an electric pre-furnace, which contained a $15 \mathrm{~m}$ circular $1 / 8^{\prime \prime}$ stainless-steel tube, for preheating, and eventually fed to the catalyst bed. About $30 \mathrm{~min}$ after feed introduction, when the products' concentration became stable, the gas products were sampled and analyzed using a gas chromatograph (GC, Varian 3400) equipped with a residual gas analyzer (RGA 200). The product sampling was repeated three times and reasonable accuracy (less than $1 \%$ difference) in the results was obtained.

Conventional Heating Setup: Similar setup to microwave was used with a difference that in these set of experiments; a quartz tubular U-shaped reactor was used to hold $0.9 \mathrm{~g}$ of catalyst. The reactor had a diameter (i.d.) of $7.9 \mathrm{~mm}$ and a length of $36.3 \mathrm{~mm}$ for holding catalysts. The reactor was heated in a furnace and the bed temperature was measured using a type $\mathrm{R}$ thermocouple placed inside the tube in the furnace. Similar operating conditions to that of the catalytic-microwave reaction was applied, and the effects of temperature and metal content were investigated and compared to the results from microwave setup.

Data Evaluation: The methane and carbon dioxide conversions and hydrogen and carbon monoxide selectivities were calculated using the following equations:

$$
X_{\mathrm{CH}_{4}}=\frac{n_{T, \text { in }} \times y_{\mathrm{CH} 4, \text { in }} n_{T, \text { out }} \times y_{\mathrm{CH} 4, \text { out }}}{n_{T, \text { in }} \times y_{\mathrm{CH}, \text { in }}} \times 100
$$




$$
\begin{gathered}
X_{\mathrm{CO}_{2}}=\frac{n_{T, \text { in }} \times y_{\mathrm{CO} 2, \text { in }} n_{T, \text { out }} \times y_{\mathrm{CO} 2 \text { out }}}{n_{T, \text { in }} \times y_{\mathrm{CO}, \text { in }}} \times 100 \\
S_{\mathrm{H}_{2}}=\frac{n_{T, \text { out }} \times y_{\mathrm{H} 2, \text { out }}}{n_{T, \text { in }}-\left(n_{T, \text { out }} \times y_{\mathrm{CH} 4 \text { out }}+n_{T, \text { out }} \times y_{\mathrm{CO} 2, \text { out }}\right)} \times 100 \\
S_{\mathrm{CO}}=\frac{n_{T, \text { out }} \times y_{\mathrm{CO}, \text { out }}}{n_{T, \text { in }}-\left(n_{T, \text { out }} \times y_{\mathrm{CH} 4 \text { out }}+n_{T, \text { out }} \times y_{\mathrm{CO} 2, \text { out }}\right)} \times 100 \\
R_{\mathrm{H} 2 / \mathrm{CO}}=\frac{n_{T, \text { out }} \times y_{\mathrm{H} 2, \text { out }}}{n_{T, \text { out }} \times y_{\mathrm{CO}, \text { out }}}
\end{gathered}
$$

where $\mathrm{X}$ is the conversion, $\mathrm{S}$ is the selectivity, $\mathrm{y}$ is the mole fraction, $n_{T, i n}$ is the total moles of the input gases, and $n_{T, o u t}$ is the total moles of output gases.

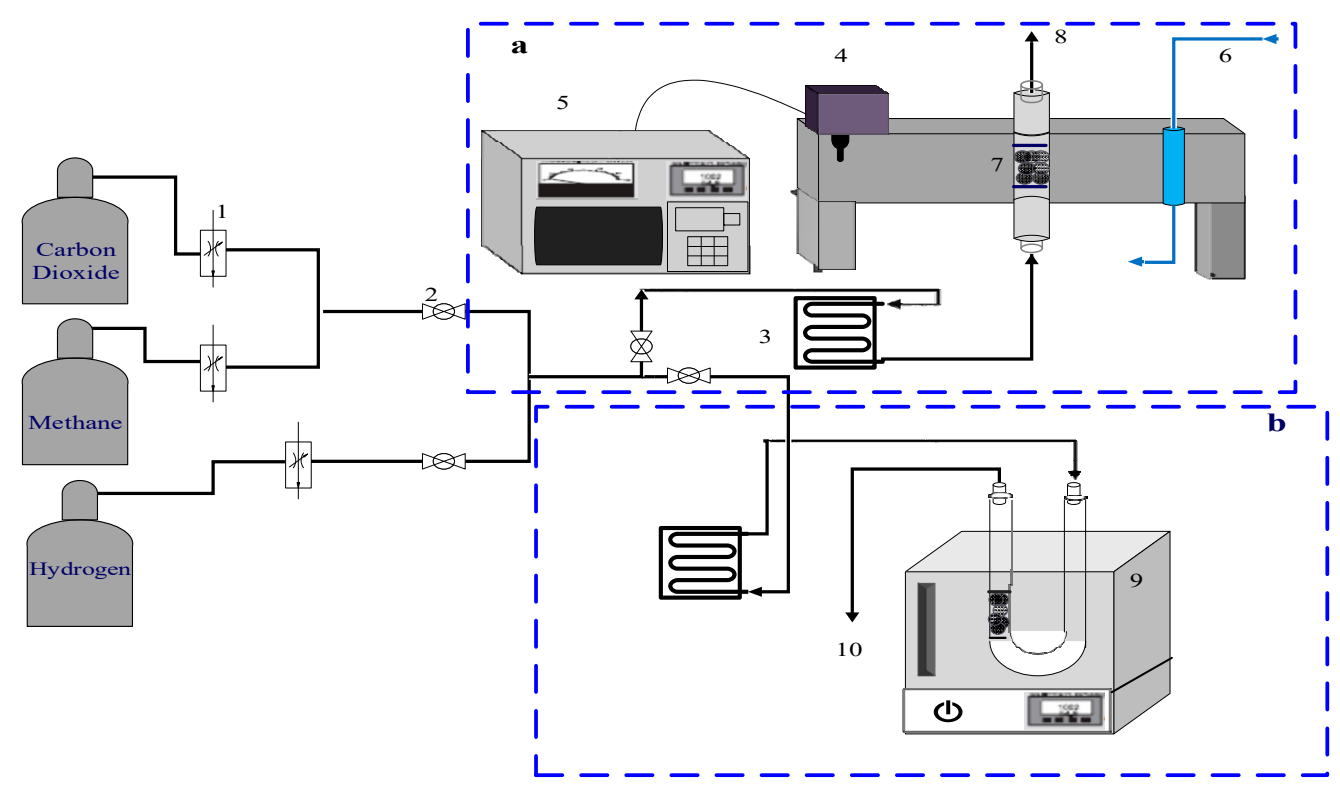

Figure 7. Schematic diagram of (a) microwave and (b) conventional setups for methane dry reforming. (1) Mass flow controller. (2) Ball valve. (3) Preheater jacket. (4) Microwave magnetron (5) Microwave power supply. (6) Cooling water. (7) Catalyst bed (quartz tube). (8) Products from microwave reactor. (9) Furnace. (10) Product from conventional reactor.

The equilibrium constant is given in terms of mole fractions y or number of moles $\mathrm{n}$ of the individual components for both methane reforming (MR) and reverse water gas shift (RWGS) reactions as follows:

$$
\begin{gathered}
k_{M R}=\frac{p_{\mathrm{H}_{2}}^{2} \cdot p_{\mathrm{CO}}^{2}}{p_{\mathrm{CO}_{2}} \cdot p_{\mathrm{CH}_{4}}}=\frac{y_{\mathrm{H}_{2}}^{2} \cdot y_{\mathrm{CO}}^{2}}{y_{\mathrm{CO}_{2}} \cdot y_{\mathrm{CH}}} \cdot P_{T o t}^{2}=\frac{n_{\mathrm{H}_{2}}^{2} \cdot n_{\mathrm{CO}}^{2}}{n_{\mathrm{CO}_{2}} \cdot n_{\mathrm{CH}_{4}} \cdot n_{\mathrm{Tot}}^{2}} \cdot P_{\mathrm{Tot}}^{2}=\exp \left(-\Delta G_{M R} / R T\right) \\
k_{R W G S}=\frac{y_{\mathrm{H}_{2} \mathrm{O}} \cdot y_{\mathrm{CO}}}{y_{\mathrm{CO}_{2}} \cdot y_{\mathrm{H}_{2}}}=\frac{n_{\mathrm{H}_{2} \mathrm{O}} \cdot n_{\mathrm{CO}}}{n_{\mathrm{CO}_{2}} \cdot n_{\mathrm{H}_{2}}}=\exp \left(-\Delta G_{R W G S} / R T\right) .
\end{gathered}
$$

In order to calculate the equilibrium conversions, the equilibrium constant was calculated by finding the Gibbs free energy. The calculations were performed using MATLAB.

\section{Conclusions}

Methane reforming by $\mathrm{CO}_{2}$ was investigated in this study over series of $\mathrm{Ni} / \mathrm{AC}, \mathrm{NiMgO} / \mathrm{AC}$, and $\mathrm{Ni} / \mathrm{MgO} / \mathrm{AC}$ catalysts using microwave as the heating source. Among Ni/AC catalysts with varying nickel loading, $15 \mathrm{Ni} / \mathrm{AC}$ showed the highest activity. The addition of $\mathrm{Mg}$ as the promoter was found to enhance the activity of the catalyst by increasing nickel dispersion. $\mathrm{H}_{2} / \mathrm{CO}$ ratio was also 
increased, indicating that with the addition of $\mathrm{Mg}$, the effect of secondary reaction was less profound. Increasing the reaction temperature was found to improve the conversion of reactants, which was expected as the reforming reaction is endothermic. Increasing the temperature from $650{ }^{\circ} \mathrm{C}$ to $730{ }^{\circ} \mathrm{C}$ showed the highest increase in conversion and $\mathrm{H}_{2} / \mathrm{CO}$ ratio.

Compared to conventional heating, applying microwave heating at the same catalyst bed temperature for both heating systems resulted in significant enhancement of the methane conversion. However, for high flow rate (GHSV of 33,000 mL/g cat.h), the conversions were below the equilibrium value. Decreasing the flow rate, the conversions passed the equilibrium values for the tested temperature $\left(650^{\circ} \mathrm{C}\right)$. The higher conversions were related to the creation of micro-plasmas or hot spots over the active sites increasing the reaction temperature higher than the measured average temperature of catalyst bed.

Reactor energy efficiency based on the outlet gas temperatures was compared between both heating mechanisms for $10 \mathrm{Ni} / \mathrm{AC}$ and $\mathrm{Ni} / \mathrm{MgO} / \mathrm{AC}$ catalysts. The microwave heating was found to have lower outlet gas temperature and higher efficiency than its conventional counterpart.

Author Contributions: Conceptualization, Y.Z.; data curation, S.S. and B.S.; formal analysis, S.S. and B.S.; methodology, S.S. and B.S.; supervision, M.E. and Y.Z.; writing-original draft, S.S. and B.S.; writing-review and editing, M.E. and Y.Z.

Funding: This research was funded by The Natural Sciences and Engineering Research Council of Canada (NSERC).

Acknowledgments: The authors gratefully acknowledge financial support from the Natural Sciences and Engineering Research Council of Canada (NSERC) Discovery Grant and Tobie Boutot for his technical support.

Conflicts of Interest: The authors declare no conflict of interest.

\section{References}

1. Wysocka, I.; Hupka, J.; Rogala, A. Catalytic Activity of Nickel and Ruthenium-Nickel Catalysts Supported on $\mathrm{SiO}_{2}, \mathrm{ZrO}_{2}, \mathrm{Al}_{2} \mathrm{O}_{3}$, and $\mathrm{MgAl}_{2} \mathrm{O}_{4}$ in a Dry Reforming Process. Catalysts 2019, 9, 540. [CrossRef]

2. Chun, S.M.; Shin, D.H.; Ma, S.H.; Yang, G.W.; Hong, Y.C. $\mathrm{CO}_{2}$ Microwave Plasma-Catalytic Reactor for Efficient Reforming of Methane to Syngas. Catalysts 2019, 9, 292. [CrossRef]

3. Kumar, A. Low Temperature Activation of Carbon Dioxide by Ammonia in Methane Dry Reforming-A Thermodynamic Study. Catalysts 2018, 8, 481. [CrossRef]

4. Chung, W.C.; Chang, M.B. Dry reforming of methane by combined spark discharge with a ferroelectric. Energy Convers. Manag. 2016, 124, 305-314. [CrossRef]

5. Hamzehlouia, S.; Jaffer, S.A.; Chaouki, J. Microwave Heating-Assisted Catalytic Dry Reforming of Methane to Syngas. Sci. Rep. 2018, 8, 8940. [CrossRef] [PubMed]

6. Choudhary, T.V.; Choudhary, V.R. Energy-Efficient Syngas Production through Catalytic Oxy-Methane Reforming Reactions. Angew. Chem. Int. Ed. 2008, 47, 1828-1847. [CrossRef] [PubMed]

7. Abdullah, A.Z.; Bhatia, S.; Fan, M.-S.; Fan, M. Catalytic Technology for Carbon Dioxide Reforming of Methane to Synthesis Gas. ChemCatChem 2009, 1, 192-208.

8. Caddick, S.; Fitzmaurice, R.; Li, H.; Nguyen, N.; Fronczek, F.R.; Vicente, M.G.H. Microwave enhanced synthesis. Tetrahedron 2009, 65, 3315-3323. [CrossRef]

9. $\mathrm{Ku}, \mathrm{H} . ;$ Siores, E.; Taube, A.; Ball, J. Productivity improvement through the use of industrial microwave technologies. Comput. Ind. Eng. 2002, 42, 281-290. [CrossRef]

10. De la Hoz, A.; Diaz-Ortiz, A.; Moreno, A. Microwaves in organic synthesis. Thermal and non-thermal microwave effects. Chem. Soc. Rev. 2005, 34, 164-178. [CrossRef]

11. Gude, V.; Patil, P.; Martinez-Guerra, E.; Deng, S.; Nirmalakhandan, N. Microwave energy potential for biodiesel production. Sustain. Chem. Process. 2013, 1, 5. [CrossRef]

12. Xiong, L.; Yu, M.; Liu, J.; Li, S.; Xue, B. Preparation and evaluation of the microwave absorption properties of template-free graphene foam-supported Ni nanoparticles. RSC Adv. 2017, 7, 14733-14741. [CrossRef]

13. Yang, Y.C.; Lee, B.J;; Chun, Y.N. Characteristics of methane reforming using gliding arc reactor. Energy 2009, 34, 172-177. [CrossRef]

14. Heintze, M.; Pietruszka, B. Plasma catalytic conversion of methane into syngas: The combined effect of discharge activation and catalysis. Catal. Today 2004, 89, 21-25. [CrossRef] 
15. Wang, Y.F.; Tsai, C.H.; Chang, W.Y.; Kuo, Y.M. Methane steam reforming for producing hydrogen in an atmospheric-pressure microwave plasma reactor. Int. J. Hydrogen Energy 2010, 35, 135-140. [CrossRef]

16. Zeng, Y.; Zhu, X.; Mei, D.; Ashford, B.; Tu, X. Plasma-catalytic dry reforming of methane over $\gamma-\mathrm{Al}_{2} \mathrm{O}_{3}$ supported metal catalysts. Catal. Today 2015, 256, 80-87. [CrossRef]

17. Kraus, M.; Egli, W.; Haffner, K.; Eliasson, B.; Kogelschatz, U.; Wokaun, A. Investigation of mechanistic aspects of the catalytic $\mathrm{CO}_{2}$ reforming of methane in a dielectric-barrier discharge using optical emission spectroscopy and kinetic modeling. Phys. Chem. Chem. Phys. 2002, 4, 668-675. [CrossRef]

18. Kalai, D.Y.; Stangeland, K.; Jin, Y.; Tucho, W.M.; Yu, Z. Biogas dry reforming for syngas production on La promoted hydrotalcite-derived Ni catalysts. Int. J. Hydrogen Energy 2018, 43, 19438-19450. [CrossRef]

19. Solsona, B.; Concepción, P.; Nieto, J.M.L.; Dejoz, A.; Cecilia, J.A.; Agouram, S.; Soriano, M.D.; Torres, V.; Jiménez-Jiménez, J.; Castellón, E.R. Nickel oxide supported on porous clay heterostructures as selective catalysts for the oxidative dehydrogenation of ethane. Catal. Sci. Technol. 2016, 6, 3419-3429. [CrossRef]

20. Parmaliana, A.; Arena, F.; Frusteri, F.; Giordano, N. Temperature-programmed reduction study of NiO?MgO interactions in magnesia-supported $\mathrm{Ni}$ catalysts and $\mathrm{NiO}$ ?MgO physical mixture. J. Chem. Soc. Faraday Trans. 1990, 86, 2663. [CrossRef]

21. Zlotorzynski, A. The Application of Microwave Radiation to Analytical and Environmental Chemistry. Crit. Rev. Anal. Chem. 1995, 25, 43-76. [CrossRef]

22. Meredith, R.J. Engineers' Handbook of Industrial Microwave Heating, Iet; The Institution of Electrical Engineers: London, UK, 1998.

23. Domínguez, A.; Fernández, Y.; Fidalgo, B.; Pis, J.; Menéndez, J. Biogas to syngas by microwave-assisted dry reforming in the presence of char. Energy Fuels 2007, 21, 2066-2071. [CrossRef]

24. Stuerga, D.; Gaillard, P. Microwave heating as a new way to induce localized enhancements of reaction rate. Non-isothermal and heterogeneous kinetics. Tetrahedron 1996, 52, 5505-5510. [CrossRef]

25. Will, H.; Scholz, P.; Ondruschka, B. Heterogeneous Gas-Phase Catalysis Under Microwave Irradiation-A New Multi-Mode Microwave Applicator. Top. Catal. 2004, 29, 175-182. [CrossRef]

26. Zhang, X.; Hayward, D.O.; Mingos, D.M.P. Effects of Microwave Dielectric Heating on Heterogeneous Catalysis. Catal. Lett. 2003, 88, 33-38. [CrossRef]

27. Durka, T.; Stefanidis, G.D.; Van Gerven, T.; Stankiewicz, A.I. Microwave-activated methanol steam reforming for hydrogen production. Int. J. Hydrogen Energy 2011, 36, 12843-12852. [CrossRef] 